\title{
EFEITOS DA APLICAÇÃO TÓPICA DO MEL DE MELIPONA SUBNITIDA EM FERIDAS INFECTADAS DE RATOS
}

\author{
EFFECTS OF TOPICAL APPLICATION OF THE HONEY OF MELIPONA SUBNITIDA IN \\ INFECTED WOUNDS OF RATS
}

\author{
Diego Felipe Sampaio Alves $\mathbf{1}$; Francisco das Chagas Cabral Júnior ${ }^{1}$; \\ Pedro Paulo de Arruda Câmara Cabral ${ }^{1}$; Ruy Medeiros de Oliveira Junior ${ }^{1}$; \\ Amália Cínthia Meneses do Rego ${ }^{2}$; Aldo Cunha Medeiros, TCBC-RN ${ }^{3}$
}

\begin{abstract}
RESUMO: Objetivo: Avaliar efeitos do uso tópico do mel da abelha silvestre Melipona subnitida na evolução de feridas infectadas de pele. Método: Ratos Wistar foram distribuídos aleatoriamente em grupos de 6, anestesiados com tiopental sódico $20 \mathrm{mg} / \mathrm{Kg}$ IP e cetamina $30 \mathrm{mg} / \mathrm{Kg}$ IM e submetidos a exérese de segmento de $1 \mathrm{~cm}^{2}$ de pele total do dorso. Os ratos do grupo C (não infectado) foram tratados com solução salina sobre a ferida diariamente e no grupo MEL (não infectado) as feridas foram tratadas com mel uma vez por dia. Nos grupos C/I e MEL/I as feridas foram inoculadas com solução polimicrobiana. Culturas foram feitas 24 horas após. Caracterizada a infecção, as feridas foram tratadas com solução salina e mel, respectivamente. No terceiro dia de tratamento foi feita nova cultura. Após epitelização foi contado o tempo de cicatrização e as feridas foram biopsiadas para histopatologia e dosagem de TNF- $\alpha$, IL-1 $\beta$ e IL-6 no tecido. Resultados: O tempo médio de cicatrização do grupo MEL/I foi menor que nos demais grupos $(\mathrm{P}<0,05)$. Verificou-se que a densidade de colágeno, leucócitos, fibroblastos e dosagem de citocinas (especialmente TNF) foi maior no grupo infectado e tratado com mel que nos demais grupos. Houve significante redução de bactérias Gram-negativas e positivas nas feridas após o tratamento com mel. Conclusão: O uso tópico de mel de Melipona subnitida em feridas infectadas da pele de ratos estimulou a resposta imunológica, reduziu a infecção e o tempo de cicatrização (Rev. Col. Bras. Cir. 2008; 35(3): 188-193)
\end{abstract}

Descritores: Mel; Abelha; Himenópteros/classificação; Cicatrização de feridas; Citocinas; Agentes antibacterianos/uso terapêutico; Infecção; rato.

\section{INTRODUÇÃO}

O tratamento de feridas infectadas continua sendo um tema de grande importância médica, particularmente na prática cirúrgica, numa época em que o uso indiscriminado de antimicrobianos tem dificultado o tratamento hospitalar dos pacientes, com repercussão no aparecimento cada vez maior de microorganismos resistentes aos antimicrobianos. Diversas terapias alternativas têm sido testadas, dentre as quais o uso tópico de substâncias com elevada osmolaridade ${ }^{1}$, sendo o açúcar e seus derivados citados como agentes cicatrizantes e antimicrobianos ${ }^{2,3}$. Nesse sentido, o uso do mel de abelha como elemento terapêutico tem mostrado resultados promissores. Tem sido demonstrada sua atividade como antibacteriano e facilitador da cicatrização no tratamento de feridas ${ }^{4}$ e queimaduras, atuando como importante barreira viscosa, impedindo a entrada de substâncias e a perda de fluidos para o meio externo ${ }^{5,6}$. A atividade antibacteriana do mel ocorre devido à sua alta osmolaridade, que o faz agir como bactericida e bacteriostático ${ }^{7}$. Estudos in vitro têm observado que o mel é eficaz contra bactérias antibiótico-resistentes como o Estaphylococcus aureus e Pseudomonas aeruginosa ${ }^{8-11}$.
Tendo em vista estas propriedades do mel de abelha, o presente trabalho teve como objetivo avaliar a influência do mel de Melipona subnitida, abelha silvestre comum no nordeste Brasileiro, conhecida como Jandaíra, no tratamento de feridas infectadas da pele de ratos.

\section{MÉTODO}

Foram usados 24 ratos da raça Wistar, com peso de $221 \pm 18 \mathrm{~g}$, provenientes do Biotério do Núcleo de Cirurgia Experimental da Universidade Federal do Rio Grande do Norte. O protocolo foi aprovado pelo Comitê Institucional de Ética em Pesquisa e o manuseio dos animais seguiu as normas e orientações do Colégio Brasileiro de Experimentação Animal (COBEA). Foram selecionados aleatoriamente e alocados em quatro grupos, com seis ratos cada: Grupo $\mathrm{C}$ - ratos com feridas não infectadas, submetidos a tratamento tópico com solução salina $0,9 \%$. Grupo C/I - ratos com feridas infectadas tratadas com solução salina. Grupo MEL - ratos com feridas não infectadas tratadas com mel. Grupo MEL/I - ratos com feridas infectadas tratadas com mel.

Metodologia empregada na confecção das feridas Os ratos foram anestesiados com tiopental sódico $20 \mathrm{mg} / \mathrm{Kg}$

1. Aluno do Curso de Medicina; Programa de Iniciação Científica, Universidade Federal do Rio Grande do Norte (UFRN), Natal - RN.

2. Mestranda do Programa de Pós-Graduação em Ciências da Saúde, UFRN, Natal - RN.

3. Professor Titular Doutor, Chefe da Disciplina de Técnica Operatória, Coordenador do Programa de Pós-graduação em Ciências da Saúde, UFRN, Natal - RN.

Recebido em 14/01/2008

Aceito para publicação em 13/03/2008

Conflito de interesses: nenhum

Fonte de financiamento: $\mathrm{CNPq}$

Trabalho realizado no Programa de Iniciação Científica da Universidade Federal do Rio Grande do Norte (UFRN) Natal - RN 


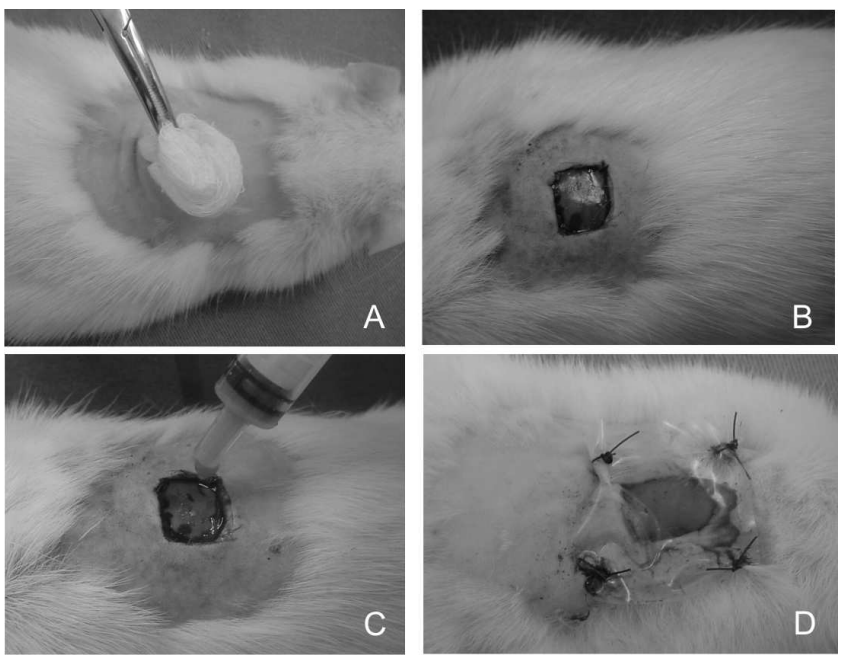

Figura 1 - 1A, antissepsia da pele com álcool a 70\%; 1B, Excisão de $1 \mathrm{~cm}^{2}$ de fragmento de pele do dorso do animal; $1 C$, inoculação com solução polimicrobiana; $1 D$, proteção da ferida com lâmina de polietileno fixada com fio de nylon 4-0.

IP e cetamina $30 \mathrm{mg} / \mathrm{Kg}$ IM, submetidos à depilação da pele dorsal e antissepsia com álcool 70\% (Figura 1A). Posteriormente, foi provocada uma ferida aberta pela retirada de um fragmento de $1 \mathrm{~cm}^{2}$ de pele total do dorso (Figura 1B). Nos grupos de feridas infectadas C/I e MEL/I as feridas foram inoculadas com duas gotas de solução polimicrobiana de fezes frescas dos próprios animais (Figura 1C). Esta solução foi preparada diluindo-se $1 \mathrm{~g}$ de fezes em $10 \mathrm{ml}$ de solução salina estéril com posterior tamização com gaze dobrada quatro vezes. As feridas de todos os animais foram cobertas com lâmina de polietileno esterilizada, fixada sobre a lesão com quatro pontos simples de monofilamento de nylon 4-0 (Figura 1D). A dor pós-operatória foi tratada com tenoxicam (Roche Farm., Brasil); $10 \mathrm{mg} / \mathrm{Kg}$ foram injetados no subcutâneo uma vez por dia durante três dias.

Tratamento das feridas - Nos animais dos Grupos C (não infectado) e C/I (infectado) as feridas receberam tratamento tópico com uma dose diária de duas gotas de solução salina. Nos Grupos MEL (não infectado) e MEL/I (infectado) as feridas foram tratadas com duas gotas de mel, uma vez por dia.

Análise do mel - Foi utilizado o mel da abelha Melipona subnitida adquirido do C. Sertanejo, Natal-RN, Brasil. A análise físico-química do mel foi realizada no Laboratório de Tecnologia de Alimentos do Departamento de Farmácia da UFRN. Todos os parâmetros analisados foram resultantes da média de três repetições. A umidade das amostras foi determinada por meio de um refratômetro Abbe com escala de refração (ND) 1300-1720 e 0-95\%, temperatura de $20^{\circ} \mathrm{C}$, modelo 2 Waj, Biobrix, São Paulo, Brasil. A prova do Hidroximetilfurfural (HMF) foi realizada para se verificar a possibilidade de adulteração por adição de açúcar, estocagem inadequada ou superaquecimento, através da determinação da absorbância da amostra, utilizando espectrofotômetro digital, com faixa de 200-1000 $\mathrm{nm}$ (monofeixe), banda de passagem de $5 \mathrm{~nm}$ (fixa), modelo SP-
220, Bioespectro, São Paulo, Brasil. O teor de cinzas das amostras foi determinado em forno mufla Splabor, São Paulo, Brasil, a $600^{\circ} \mathrm{C}$ por cinco horas, com temperatura máxima de trabalho permitida $1.100^{\circ} \mathrm{C}$. Foi utilizado o $\mathrm{pHmetro}$ digital de bancada modelo pH21, Hanna Instruments, São Paulo, Brasil, para a medida do $\mathrm{pH}$ e a acidez total foi dosada pelo método da titulação simples. Sólidos insolúveis em água foram determinados com uso de estufa 515-Fanem, São Paulo, Brasil, a $135^{\circ} \mathrm{C}$, após lavagem do mel em água a $80^{\circ} \mathrm{C}$ para eliminação de açúcares. Todos esses parâmetros foram comparados com os estabelecidos pelo Regulamento Técnico de Identidade e Qualidade do mel do Ministério da Agricultura, Brasil, 200012. Análise microbiológica do mel foi feita utilizando-se os meios de cultura agar sangue e agar McConkey.

\section{Procedimentos utilizados para avaliação das feridas}

- Vinte e quatro horas após a inoculação, foi feita coleta de secreção de todas as feridas com swab estéril para cultura microbiológica, utilizando os meios agar sangue e agar McConkey para identificação de microrganismos Gram positivos e Gram negativos respectivamente. No terceiro dia de tratamento foi feita nova cultura para se verificar a ação do mel sobre os microrganismos identificados na primeira cultura.

Foi considerado tempo de cicatrização o intervalo entre a confecção da ferida e a manhã em que as feridas apresentavam-se completamente epitelizadas. Após epitelização as feridas foram biopsiadas, utilizando-se metade dos materiais para dosagem de citocinas teciduais e outra metade para histopatologia. Os materiais foram triturados e o homogeneizado foi utilizado para dosagem das citocinas fator de necrose tumoral alfa (TNF- $\alpha$ ), interleucina-1 beta (IL-1 $\beta$ ) e interleucina 6 (IL-6), utilizando-se Kit Preprotec, USA, e técnica ELISA. Um segmento de cada ferida foi fixado em formalina $10 \%$ e incluído em parafina. Cortes de $5 \mu \mathrm{m}$ foram corados com hematoxilina e eosina e analisados através de microscopia óptica por patologista experiente, sem conhecimento prévio dos respectivos grupos. A análise quantitativa foi feita quanto ao montante de leucócitos, fibroblastos e fibras colágenas, utilizando um sistema digitalizador e analisador de imagens. A área total dos campos microscópicos foi observada em microscópio óptico (Olympus BX50), cuja imagem foi capturada por câmera Samsung de alta resolução e digitalizada através do Software Image Pro-plus, (Media Cybernetics- LP, USA). Cada campo digitalizado foi quantificado em unidades pixel com coordenadas definidas, sendo avaliados cinco campos microscópicos aleatórios por lâmina. Após selecionada a resolução desejada, as imagens foram armazenadas para quantificação da densidade da reação inflamatória.

Estatística-Aavaliação estatística foi realizada por meio da análise de variância (ANOVA), seguida pelo teste de Bonferroni, considerando-se diferenças significantes quando $\mathrm{p}<0,05$.

\section{RESULTADOS}

A análise físico-química do mel utilizado demonstrou que todos os parâmetros estavam de acordo com o estabelecido pelas normas do Ministério da Agricultura, Brasil, podendo ser considerado de boa qualidade (Tabela 1). O exame de 
Tabela 1 - Parâmetros da análise físico-química do mel de Melipona subnitida (jandaíra), comparados com os estabelecidos pela legislação do Ministério da Agricultura-Brasil.

\begin{tabular}{lcccccc}
\hline Amostras & Umidade (\%) & HMF $(\mathbf{m g} / \mathbf{K g})$ & $\mathbf{p H}$ & \multicolumn{2}{c}{ Acidez (meq/kg) } & Cinzas (\%) Sólidos Insolúveis (\%) \\
Mel de jandaíra & 18,06 & 23,90 & 3,85 & 41,66 & 0,01 & 0,01 \\
Referência: & Máximo 20 & Máximo 40 & $3,3 \mathrm{a} 4,6$ & Máximo 50 & Máximo 0,6 & Máximo 0,1 \\
Ministério Agricultura & & & & & & \\
\hline
\end{tabular}

$H M F$, hidroximetilfurfural.

cultura revelou que o mel não apresentava contaminação bacteriana.

Não houve diferença significante no tempo de cicatrização das feridas dos animais dos Grupos C, C/I e MEL (p>0,05) (Tabela 2). Entretanto, quando feridas infectadas foram tratadas com mel (Grupo MEL/I), observou-se diminuição significante no tempo de cicatrização, quando comparado com os demais grupos. (Figura 2)

O tratamento de feridas infectadas com mel (Grupo MEL/I) resultou em reação cicatricial com densidade de colágeno, leucócitos e fibroblastos significativamente maior do que nos demais grupos. Igualmente, a presença do mel em feridas não infectadas fez surgir colágeno, leucócitos e fibroblastos com densidade maior do que no Grupo controle (C), caracterizando diferença significante $(\mathrm{p}<0,05)$ ( Tabela 3$)$.

A presença do mel de abelha em feridas não infectadas (Grupo MEL) estimulou a produção das citocinas TNF- $\alpha$ e IL$1 \beta$, uma vez que, comparando-se os valores com os observados nas feridas dos ratos controles, as diferenças foram estatisticamente significantes $(\mathrm{p}<0,05)$. Quanto à IL-6, não foi detectado aumento significante na dosagem tecidual no grupo MEL, quando comparado ao controle (Tabela 4). Nos tecidos cicatriciais das feridas infectadas tratadas com mel (Grupo MEL/ I) foi observado um aumento significante $(\mathrm{p}<0,05)$ da expressão das citocinas TNF $\alpha$, IL-1 $\beta$ e IL-6, em comparação com as
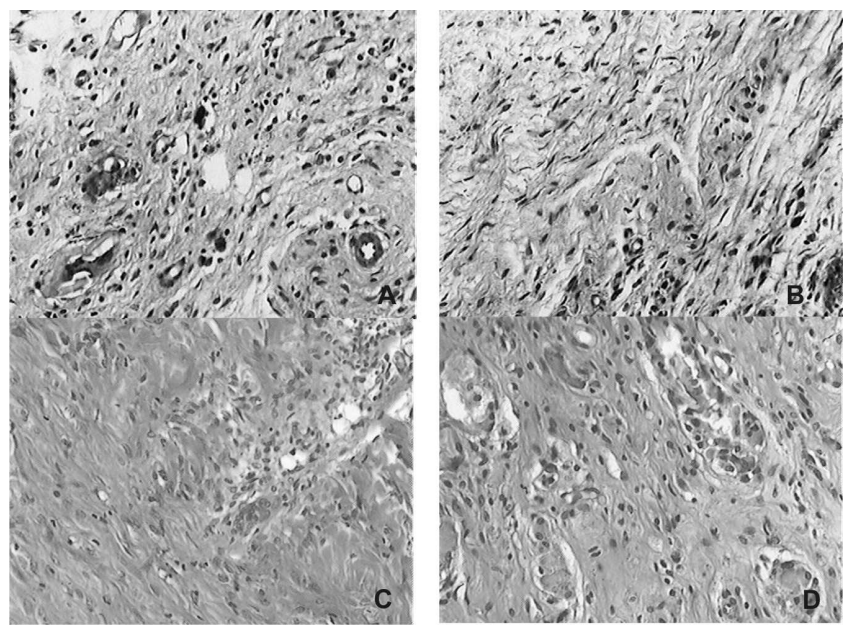

Figura 2 - Estudo histológico da cicatrização das feridas. A: densidade do colágeno, leucócitos e fibroblastos em lâmina de animal do grupo controle. B: a densidade dos elementos estudados mostra-se maior no grupo MEL do que no grupo controle. C: aspecto histológico de ferida infectada tratada com solução salina (grupo C/I). D: alta densidade de leucócitos, colágeno/fibroblastos em animal do grupo MELI. (HE, 100x). feridas infectadas tratadas com solução salina (Grupo C/I) (Tabela 4)

Na secreção das feridas limpas dos animais dos Grupos C e MEL não ocorreu crescimento de microrganismos nos meios de cultura. Nas feridas infectadas tratadas com solução salina (Grupo C/I) foi observado crescimento de bactérias Grampositivas (Staphylococcus sp) e Gram-negativas (Proteus mirabilis, Klebsiella sp, Acinetobacter sp, Escherichia coli e Pseudomonas $s p$ ) na primeira cultura, 24 horas após a inoculação das feridas. Na segunda cultura de secreção colhida no terceiro dia de observação as mesmas bactérias estavam presentes nos meios de cultura. Nos animais cujas feridas infectadas foram tratadas com mel (MEL/I) observou-se que em $100 \%$ dos casos o tratamento foi eficaz na eliminação de microrganismos Gram-negativos como Pseudomonas $s p$, Klebsiella sp, Acinetobacter sp e Escherichia coli. O mel de Melipona subnitida inibiu com menor eficácia, porém de modo significante, o crescimento de Proteus mirabilis e de Staphylococcus sp. Esse efeito ocorreu em 50\% dos espécimes em que esses microrganismos estiveram presentes nas feridas infectadas, por ocasião da primeira cultura (Tabela 5).

\section{DISCUSSÃO}

Nos últimos cinco anos tem aumentado o interesse pelo uso do mel de abelhas no tratamento de feridas, mas ainda há pouca evidência científica para dar suporte ao seu uso tópico em feridas e queimaduras ${ }^{13}$. No presente trabalho, foram estudados os efeitos em feridas infectadas, do mel de Melipona subnitida, uma abelha silvestre sem ferrão, conhecida como Jandaíra, comum na região do semi-árido do Nordeste do Brasil. Seu mel tem sido utilizado empiricamente na medicina popular para tratamento de doenças respiratórias, doenças de pele e tecidos moles, e não há na literatura relatos a respeito do seu uso para tratamento de feridas limpas e

Tabela 2 - Comparação do tempo de cicatrização entre os grupos estudados.

\begin{tabular}{ll}
\hline Grupos & Dias \\
\hline $\mathrm{C}$ & $13,5 \pm 0,86$ \\
$\mathrm{C} / \mathrm{I}$ & $14,0 \pm 2,5$ \\
MEL & $14,0 \pm 2,6$ \\
MEL/I & $11,3 \pm 2,2 *$ \\
\hline
\end{tabular}

* $P<0,05$ comparado com $C$, C/I e MEL. 
Tabela 3 - Densidade do colágeno e fibroblastos na pele de ratos tratados ou não tratados com mel de abelha jandaíra.

\begin{tabular}{llccr}
\hline Animal & Grupo C & $\begin{array}{c}\text { Observação até a Epitelização das Feridas } \\
\text { Grupo C/I }\end{array}$ & GrupoMEL & GrupoMEL/I \\
\hline 1 & 433,87 & 228,90 & 772,12 & 890,84 \\
2 & 386,40 & 350,23 & 653,28 & 1137,30 \\
3 & 543,22 & 280,78 & 681,40 & 1256,89 \\
4 & 456,66 & 321,67 & 802,43 & 1103,65 \\
5 & 397,12 & 255,88 & 744,27 & 950,12 \\
6 & 427,80 & 402,90 & 651,89 & 933,50 \\
Média $\pm d p$ & $440,8 \pm 56,2$ & $306,7 \pm 64,3$ & $717,56 \pm 64,25$ & $1045,38 \pm 142,8 *$ \\
\hline
\end{tabular}

*Diferença significante pelo teste t de Bonferroni, comparado com os grupos $C, C / I, M E L(p<0,05)$.

Tabela 4 - Dosagem de citocinas de acordo com os grupos estudados.

\begin{tabular}{lccc}
\hline Grupos & TNF- $\boldsymbol{\alpha}$ & IL-1 $\boldsymbol{\beta}$ & IL-6 \\
\hline C & $77 \pm 8,2$ & $53 \pm 9,6$ & $48 \pm 7,1$ \\
MEL & $98 \pm 4,7^{*}$ & $84 \pm 8,3^{*}$ & $53 \pm 8,9$ \\
C/I & $115 \pm 12$ & $91 \pm 11$ & $84 \pm 6,6$ \\
MEL/I & $175 \pm 18,4^{* *}$ & $154 \pm 17^{* *}$ & $122 \pm 10,2^{* *}$ \\
\hline
\end{tabular}

$* p<0,05$ comparado com $C$. $* * p<0,05$ comparado com $C, M E L$, $C / I$.

infectadas. A análise microbiológica e físico-química do mel de Melipona subnitida usado na pesquisa revelou que se encontrava de acordo com as normas de qualidade estabelecidas pelo Ministério da Agricultura-Brasil, adequado para uso no presente trabalho. Para uso do mel em humanos deve ser assegurada boa procedência e segurança do ponto de vista físico-químico e microbiológico, aliado ao fato de ter boa relação custo-efetivo ${ }^{14}$.

O mel de abelhas em geral é composto por cerca de $40 \%$ de frutose, $20 \%$ de água, aminoácidos, vitaminas (ácido nicotínico, piridoxina e tiamina), enzimas (diastase, invertase, catalase e glicose-oxidase), peróxido de hidrogênio, e minerais (potássio, ferro, magnésio, fósforo, cobre, zinco e cálcio) $)^{15,16}$. Em nosso estudo, a avaliação microbiológica nas feridas infectadas dos animais dos Grupos MEL/I e C/I mostrou atividade antimicrobiana do mel da abelha Melipona subnitida contra bactérias Gram-negativas, incluindo seu efeito antiPseudomonas. Os resultados desse estudo também mostraram claramente que o mel tem potencial para ser usado como antimicrobiano para prevenir e controlar infecções por Grampositivos (Staphylococcus). Estudo in vitro realizado por French et $a l^{17}$ demonstrou esse potencial e outros trabalhos têm apontado eficácia do mel contra cocos Gram-positivos e Pseudomonas considerados multiresistentes ${ }^{8-10}$. A atividade antibacteriana do mel está relacionada com algumas propriedades: é uma solução supersaturada com potente atividade osmótica, tem o pH entre 3,2 e 4,5 e esta acidez é suficiente para inibir o crescimento de muitos microrganismos. A propósito, o pH do mel de Melipona subnitida foi caracterizado como sendo 3,85. O peróxido de hidrogênio produzido pela glicose-oxidade é certamente o componente antibacteriano mais importante do mel e vários outros fatores fitoquímicos e

Tabela 5 - Microrganismos isolados nas feridas infectadas tratadas com mel (grupo MEL/I) na $1^{a}$ cultura 24 hapós inoculação das feridas e no $3^{\circ}$ dia de tratamento com mel.

\begin{tabular}{|c|c|c|}
\hline Raton $^{\circ}$ & $\begin{array}{l}1^{\mathrm{a}} \text { cultura } \\
(24 \text { horas após inoculação das feridas) }\end{array}$ & $\begin{array}{l}\left.2^{\mathrm{a}} \text { Cultura ( } 3^{\circ} \text { dia de tratamento com mel, }\right) \\
\text { das feridas infectadas }\end{array}$ \\
\hline 01 & $\begin{array}{l}\text { Staphylococcus } s p \\
\text { Acinetobacter sp } \\
\text { Proteus mirabilis }\end{array}$ & Proteus mirabilis \\
\hline $\mathbf{0 2}$ & $\begin{array}{l}\text { Staphylococccus } s p \\
\text { Klebsiella sp; Acinetobacter; } \\
\text { Proteus mirabilis }\end{array}$ & Staphylococcus sp \\
\hline 03 & $\begin{array}{l}\text { Staphylococus sp; Pseudomonas sp; } \\
\text { Acinetobacter; Proteus mirabilis }\end{array}$ & Proteus mirabilis \\
\hline 04 & $\begin{array}{l}\text { Staplylococcus sp; } \\
\text { Pseudomonas sp; Proteus mirabilis }\end{array}$ & Proteus mirabilis \\
\hline 05 & $\begin{array}{l}\text { Staphylococcus sp; Pseudomonas sp; } \\
\text { Acinetobacter; Proteus mirabilis }\end{array}$ & Staphylococcus sp \\
\hline 06 & $\begin{array}{l}\text { Staplylococcus sp; } \\
\text { Pseudomonas sp; Escherichia coli }\end{array}$ & Staphylococcus sp \\
\hline
\end{tabular}


imunoquímicos estão sendo avaliados ${ }^{7,16}$. Estudo comparativo entre mel e açúcar demonstrou que o mel é mais eficaz contra infecção de feridas ${ }^{18}$.

No presente estudo a análise histopatológica das lesões infectadas e tratadas com mel revelou significante aumento da presença de leucócitos, notadamente macrófagos, fibroblastos e colágeno nos tecidos examinados. Macrófagos são células importantes para a regulação da cicatrização de feridas, de modo que substâncias tópicas que ativam macrófagos podem gerar estímulo pró-inflamatório, proliferação celular e progressão do processo cicatricial ${ }^{19}$.

Estabelecidos os efeitos do mel de abelhas em feridas limpas e infectadas, resta o esclarecimento a respeito dos mecanismos responsáveis pela aceleração do processo de cicatrização e atividade antimicrobiana. Estudos têm mostrado que o efeito do mel na cicatrização de feridas pode estar relacionado ao aumento na liberação de TNF- $\alpha^{20}$. No presente trabalho conseguimos detectar que a maior expressão de citocinas ocorreu com o TNF- $\alpha$, seguido das interleuninas IL-1 $\beta$ e IL-6 nos tecidos de feridas infectadas e tratadas com mel. Este achado pode em parte explicar a aceleração da cicatrização dessas feridas quando comparado com aquelas não tratadas com mel. De fato, após estudo realizado por Tonks et $a l^{21}$ em que utilizaram mel de abelha e mel artificial para elucidar a liberação das citocinas TNF- $\alpha$, IL-1 $\beta$ e IL-6 por monócitos, foi sugerido que os efeitos regulatórios do mel sobre a cicatrização das feridas estão relacionados a outros componentes além dos açúcares presentes no mel, alguns fatores ainda desconhecidos, que induzem a liberação de citocinas. Seu estudo demonstrou que a atividade dos monócitos, intimamente envolvidos na cicatrização das feridas, é modulada pelo mel. Entretanto, os mecanismos pelos quais o mel afeta a liberação de agentes antiinflamatórios, pró-inflamatórios e fatores do crescimento são desconhecidos, podendo atuar em monócitos, macrófagos, células endoteliais e fibroblastos.

Em conclusão, nossos achados sugerem que parte da eficácia do mel de Melipona subnitida em melhorar a cicatrização e tratar a infecção em feridas pode ser devida a um incremento na defesa imunológica orgânica e tecidual, além de sua atividade antimicrobiana.

\begin{abstract}
Background: The current study investigated the antimicrobial, immunological and healing effects of Melipona subnitida honey on infected wounds of rat skin. Method: Wistar rats were anesthetized with sodium thiopental $20 \mathrm{mg} / \mathrm{Kg} I P$ and ketamine $30 \mathrm{mg} /$ $\mathrm{kg} I M$. We evaluated the effects of honey using rats by generating $1 \mathrm{~cm}^{2}$ full-thickness skin wounds on the dorsum. The wounds of Group C rats (not infected) were treated daily with topic saline solution (0.9\%) and in the Group HONEY (not infected) the wounds were treated with topic honey once a day. In the Groups C/I (infected) and HONEY/I (infected) the wounds were inoculated with polymicrobial solution, and tissue bacterial culture was performed 24 hours later. These wounds were treated with topic saline solution and honey, respectively. In the third day of treatment it was made a new bacterial culture. After epithelialization, wound tissue biopsies were used for cytokines dosage and histology. Results: The HONEY/I wounds showed more rapid healing and re-epithelialization than in the other groups, and the difference was significant ( $p<0.05)$. It was observed that the density of collagen, fibroblasts, macrophages and the expression of TNF-á, IL1-â and Il-6 were higher on the HONEY/I wounds then in the other groups. After the treatment with honey, the amount of Gram-positive and Gram-negative bacteria in the infected wounds decreased significantly. Conclusion: The results may encourage the use of honey in skin infected wounds because it stimulated cytokine production, reduced the healing time and had antibacterial activity.
\end{abstract}

Key words: Honey; Bee; Hymenoptera/classification; Wound Healing; Cytokines; Anti-bacterial agents/ therapeutic use; Infection; Rat.

\section{REFERÊNCIAS}

1. Vermeulen H, Ubbink DT, Goossens A, de Vos R, Legemate DA. Systematic review of dressings and topical agents for surgical wounds healing by secondary intention. Br J Surg. 2005; 92(6):665-72.

2. Blaser G, Santos K, Bode U, Vetter H, Simon A. Effect of medical honey on wounds colonised or infected with MRSA. J Wound Care. 2007; 16(8):325-8.

3. Coelho COC, Carrazoni PG, Monteiro VLC, Melo FAD, Mota A, Filho FT. Biopolímero produzido a partir da cana-de-açúcar para cicatrização cutânea. Acta Cir Bras. 2001;17(supl.1):11-3.

4. Visavadia BG, Honeysett J, Danford MH. Manuka honey dressing: an effective treatment for chronic wound infections. $\mathrm{Br}$ J Oral Maxillofac Surg. 2008; 46(1):55-6. Epub 2006 Nov 20.

5. Postmes T, van den Bogaard AE, Hazen M. Honey for wounds, ulcers, and skin graft preservation. Lancet. 1993; 341(8847):756-7.
6. Subrahmanyam M, Shahapure AG, Nagne NS, Bhagwat VR, Ganu JV. Effects of topical application of honey on burn wound healing. Ann Burns Fire Disast. 2001; 14(1):143-5.

7. Jeddar A, Kharsany A, Ramsaroop UG, Bhamjee A, Haffejee IE, Moosa A. The antibacterial action of honey. An in vitro study. S Afr Med J. 1985; 67(7):257-8.

8. Cooper RA, Molan PC, Harding KG. Antibacterial activity of honey against strains of Staphylococcus aureus from infected wounds. J R Soc Med. 1999; 92(6):283-5.

9. Cooper RA, Molan PC, Harding KG. The sensitivity to honey and Gram- positive cocci of clinical significance isolated from wounds. J Appl Microbiol. 2002; 93(5):857-63.

10. Cooper RA, Halas E, Molan PC. The efficacy of honey in inhibiting strains of Pseudomonas aeruginosa from infected burns. J Burn Care Rehabil. 2002; 23(6):366-70.

11. Karayil S, Deshpande SD, Koppikar GV. Effect of honey on multidrug resistant organisms and its synergistic action with three common antibiotics. J Postgrad Med. 1998; 44(4):93-6. 
12. BRASIL. Ministério da Agricultura. Instrução normativa n. 11, de 20 de outubro de 2000. Regulamento técnico de identidade e qualidade do mel. Diário Oficial da União, Brasília, 20 out. 2000. Seção 1, p. 16-17.

13. Gethin $\mathrm{G}$. Is there enough clinical evidence to use honey to manage wounds? J Wound Care. 2004; 13(7):275-8.

14. Ingle R, Levin J, Polinder K. Wound healing with honey - a randomised controlled trial. S Afr Med J. 2006; 96(9):831-5.

15. Marchini LC, Moreti ACCC, Otsuk IP. Análise de agrupamento, com base na composição físico-química, de amostras de méis produzidos por Apis mellifera L no Estado de São Paulo. Ciênc Tecnol Aliment. 2005; 25(1):8-17.

16. Wahdan HA. Causes of the antimicrobial activity of honey. Infection. 1998; 26(1):26-31.

17. French VM, Cooper RA, Molan PC. The antibacterial activity of honey against coagulase-negative staphylococci. J Antimicrob Chemother. 2005; 56(1):228-31. Epub 2005 Jun 7.

18. Mphande AN, Killowe C, Phalira S, Jones HW, Harrison WJ. Effects of honey and sugar dressings on wound healing. J Wound Care. 2007; 16(7):317-9.
19. Thomas A, Harding KG, Moore K. Alginates from wound dressings activate human macrophages to secrete tumor necrosis factor-alpha. Biomaterials. 2000; 21(17):1797-802.

20. Tonks A, Cooper RA, Price AJ, Molan PC, Jones KP. Stimulation of TNF-alpha release in monocytes by honey. Cytokine. 2001; 14(4):240-2.

21. Tonks AJ, Cooper RA, Jones KP, Blair S, Parton J, Tonks A. Honey stimulates inflammatory cytokine production from monocytes. Cytokine. 2003; 21(5):242-7.

Como citar este artigo:

Alves DF, Cabral Júnior FC, Cabral PPA, Oliveira Júnior RM, Rego AC, Medeiros AC. Efeitos da aplicação tópica do mel de melipona subnitida em feridas infectadas de ratos. Rev Col Bras Cir. [periódico na Internet] 2008; 35(3). Disponível em URL: http://www.scielo.br/rcbc

Endereço para correspondência:

Aldo da Cunha Medeiros

Av. Miguel Alcides de Araújo, 1889

59010-180 - Natal - RN

E-mail: aldo@ufrnet.br 